\title{
BMI-1 promotes invasion and metastasis in endometrial adenocarcinoma and is a poor prognostic factor
}

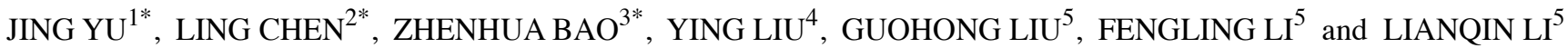 \\ ${ }^{1}$ Department of Pathology, Yantai Affiliated Hospital of Binzhou Medical University, Yantai, Shandong 264100; \\ ${ }^{2}$ Department of Obstetrics and Gynecology, First Affiliated Hospital of Shihezi University, Shihezi, Xinjiang 832001; \\ ${ }^{3}$ Department of Oncology, People's Hospital of Haiyang, Haiyang, Shandong 265100; ${ }^{4}$ Department of Physical Examination; \\ ${ }^{5}$ Department of Obstetrics and Gynecology, Yantai Affiliated Hospital of Binzhou Medical University, \\ Yantai, Shandong 264100, P.R. China
}

Received September 3, 2019; Accepted February 12, 2020

DOI: $10.3892 / o r .2020 .7539$

\begin{abstract}
Endometrial adenocarcinoma is one of the most common types of gynecological malignancies and its incidence and mortality rates are increasing. Due to tumor recurrence and metastasis, the overall five-year survival rate of patients with endometrial adenocarcinoma is shortened. The aim of the present was to investigate the role of the polycomb group protein B-lymphoma Mo-MLV insertion region 1 (BMI-1) in the invasion, metastasis and the epithelial-mesenchymal transition (EMT) of endometrial adenocarcinoma cells, as well its effects on the prognosis of patients with endometrial adenocarcinoma. Immunohistochemistry was used to examine the expression profile of BMI-1 in normal and endometrial adenocarcinoma tissues. Western blotting was used to examine the expression levels of BMI-1 and EMT markers. Kaplan-Meier plots and a Cox proportional hazards model were used to assess the overall survival. MTT cell viability assays were used to detect the proliferation of endometrial cancer cells. Transwell assays were used to examine cell migration and invasion. Small interfering RNA was used to downregulate BMI-1 expression levels, to study its effect on EMT. Immunohistochemical and clinicopathological analyses showed that BMI-1 expression was increased in endometrial adenocarcinoma tissue compared with the normal endometrial tissue $(\mathrm{P}<0.05)$. The increased expression levels of BMI-1
\end{abstract}

Correspondence to: Dr Fengling Li or Dr Lianqin Li, Department of Obstetrics and Gynecology, Yantai Affiliated Hospital of Binzhou Medical University, 717 Jinbu Street, Yantai, Shandong 264100, P.R. China

E-mail: lifengling8018@163.com

E-mail: 1ilq2005@126.com

*Contributed equally

Key words: B-lymphoma Mo-MLV insertion region 1, endometrial adenocarcinoma, clinicopathological parameters, epithelial-mesenchymal transition were closely associated with stage, myometrial invasion and lymph node metastasis $(\mathrm{P}<0.05)$. Kaplan-Meier plots and a Cox proportional hazards model showed that increased BMI-1 expression was associated with a less favorable prognosis $[\mathrm{P}=0.040$, hazards ratio $(\mathrm{HR})=1.596]$ and was associated with late-stage adenocarcinoma $(\mathrm{P}=0.006, \mathrm{HR}=1.670)$. Myometrial invasion $(\mathrm{P}=0.006, \mathrm{HR}=1.509)$ and lymph node metastasis $(\mathrm{P}=0.004, \mathrm{HR}=1.703$ ) were determined to predict a less favorable prognosis. Downregulation of BMI-1 reduced migration and invasion in endometrial cancer cells in vivo. It was also found that downregulation of BMI-1 increased the expression levels of the epithelial markers E-cadherin and keratin, and decreased the expression levels of the mesenchymal markers $\mathrm{N}$-cadherin, vimentin and the downstream transcription factor, Slug. In conclusion, BMI-1 expression was correlated with tumor invasion and metastasis, contributing to deep myometrial invasion and lymph node metastasis, and was a poor prognostic factor for endometrial adenocarcinoma.

\section{Introduction}

Worldwide, endometrial adenocarcinoma is one of the most common types of gynecological malignancies and the incidence rate is increasing (1). In the USA in 2019, it was estimated that endometrial adenocarcinoma was the fourth most common newly diagnosed type of cancer in women, with an estimated 61,880 new cases from 2015-2019 and 12,160 deaths between 2016 and 2019 and the incidence rate continues to increase (2). The clinical factors (surgical-pathological staging, depth of myometrial invasion and lymph node metastases) and biological factors (steroid receptors, growth factors, oncogenes and suppressor genes) were found to be associated with reduced survival and a less favorable disease prognosis $(3,4)$. Due to tumor recurrence and metastasis, as well as sensitivity to hormone therapy, radiotherapy and chemotherapy in certain patients, the five-year survival rate of endometrial cancer with recurrence or distant metastases is $30.8 \%$ (5), with vaginal-only recurrence it is $61 \%$ (6), which is considerably lower than the median overall five-year survival rate $87 \%$ or $85 \%(7,8)$.

BMI-1 is an oncogene and a member of the Polycomb-group family of proteins $(9,10)$. Several studies have shown that 
the expression levels of BMI-1 are upregulated in a variety of different types of cancer (11-15). Upregulated expression of BMI-1 promotes tumor cell proliferation, invasion and metastasis (16-18). In several types of cancer, BMI-1 has been reported to be poor prognostic factor (19-21). However, the expression profile of BMI-1 in endometrial cancer remains controversial. Engelsen et al (22) demonstrated that low levels of BMI-1 expression were correlated with a more aggressive phenotype of endometrial adenocarcinoma. However, Honig et al (15) showed that BMI-1 expression was higher in endometrial adenocarcinoma compared with benign endometrium samples. Our previous study showed that miR-200c inhibits epithelial-mesenchymal transition (EMT) by targeting BMI-1 via a phospho-AKT signaling pathway in endometrial cancer cells (23). However, the prognostic predictive ability of BMI-1 and its association with EMT in endometrial adenocarcinoma were not assessed. Therefore, the aim of the present study was to investigate the expression profile of BMI-1 and its association with clinicopathologic parameters as well as the prognostic value of BMI-1 expression in endometrial adenocarcinoma. BMI-1 expression was also knocked down in endometrial cancer cells to determine its role in the regulation of tumor invasion, metastasis and EMT in vitro.

\section{Materials and methods}

Patients and specimens. A total of 60 cases (age range 38-79 years, median age 59 years) of patients with endometrial adenocarcinoma, who had undergone total hysterectomy or pelvic and para-aortic lymphadenectomy simultaneously, were recruited for the present study. Cancer tissue samples were collected during the operation. A total of 40 normal endometrial specimens (age range, 38-77 years; median age, 58 years), from patients with abnormal uterine bleeding who had undergone an endometrium biopsy where the pathology results found proliferation or secretion, were collected. All tissue specimen were collected at Yantai Affiliated Hospital of Binzhou Medical University between January 2007 and December 2008. The tumors of all patients with endometrial adenocarcinoma were staged according to the 2009 International Federation of Gynecology and Obstetrics (FIGO) staging system (24). All of the specimens were fixed in $10 \%$ buffered formalin solution at room temperature for $48 \mathrm{~h}$, embedded in paraffin and consecutive $4-\mu \mathrm{m}$-thick sections were cut. None of the patients received preoperative radiotherapy, chemotherapy, hormone therapy or treatment with other medications, and had no previous history of other types of cancer. Regular follow-ups began at the day of surgery and ended after 120 months, or upon death. The present study was approved by the Ethics Committee of the Yantai Affiliated Hospital of Binzhou Medical University (Approval no. 2018-016) and the study adhered to the principles of the Declaration of Helsinki (25). Oral informed consent was obtained from each patient prior to collection of tissues.

Immunohistochemistry (IHC). Tissue sections were stained as described previously (15). Briefly, following deparaffinization in dimethylbenzene and rehydration in a series of decreasing concentrations of alcohol (100\% for $5 \mathrm{~min}, 95 \%$ for $2 \mathrm{~min}$, $80 \%$ for $2 \mathrm{~min}$ and $75 \%$ for $2 \mathrm{~min}$ ) the sections were heated in an antigen retrieval buffer pH 6.0 (EDTA, 1:300 dilution; cat. no. C1034; Beijing Solarbio Science \& Technology Co., Ltd.) at $120^{\circ} \mathrm{C}$ for $5 \mathrm{~min}$. After endogenous peroxidases were quenched with $3 \%$ hydrogen peroxide for $30 \mathrm{~min}$, the sections were incubated at $4^{\circ} \mathrm{C}$ for $24 \mathrm{~h}$ with a primary antibody against BMI-1 (1:200; cat. no. ab126738; rabbit anti-human monoclonal antibody; Abcam). The samples were subsequently incubated with biotinylated secondary goat-anti-rabbit antibodies (1:5,000; cat. no. A0208; Beyotime Institute of Biotechnology) and horseradish peroxidase labelled avidin, and the staining was developed using DAB (OriGene Technologies, Inc.).

BMI-1 staining was analyzed by two investigators who were blinded to the clinical and prognostic data. The proportion of stained cells were scored as follows: $0,<5 \%$ of cells stained; $1,5-25 \%$ of cells stained; $2,26-50 \%$ of cells stained; $3,51-75 \%$ of cells stained; or $4>75 \%$ of cells stained. The staining intensity was scored as follows: 0, no staining; 1, weak staining; 2 , medium staining; or 3, strong staining. The overall staining score was calculated as follows: Staining intensity x proportion of stained cells. Representative examples of the tissues with different staining intensities are presented as follows: -, 0-2 points;,$+ 3-4$ points;,$++ 5-8$ points; and ,+++ 9-12 points (Fig. 1).

Cell culture. The human endometrial cancer cell lines, Ishikawa cells were obtained from The Cell Bank of Type Culture Collection of the Chinese Academy of Sciences; cat. no. EB081). JEC cells were purchased from Shanghai Fusheng Industrial Co., Ltd.; cat. no. FS-0129). Both cell lines were validated using short tandem repeat DNA profiling. Both cell lines were cultured in RPMI 1640 medium (HyClone; GE Healthcare Life Sciences) with 10\% FBS (Gibco; Thermo Fisher Scientific, Inc.), $100 \mu \mathrm{g} / \mathrm{ml}$ penicillin, and $100 \mathrm{mg} / \mathrm{ml}$ streptomycin and cultured at $37^{\circ} \mathrm{C}$ in $5 \% \mathrm{CO}_{2}$ and $95 \%$ atmospheric air.

BMI-1 gene small interfering RNA (siRNA) transfection. siRNA targeting the BMI-1 gene and scrambled siRNA control were purchased from Shanghai GenePharma Co., Ltd. The si-BMI-1 sequences were as follows: Sense, 5'-CCAGAU UGAUGUCAUGUAUTT-3' and antisense, 5'-AUACAUGAC AUCAAUC-UGGTT-3'; and scramble siRNA sense 5'-UUC UCCGAACGUGCACGUTT-3', and antisense, 5'-ACGUGA CAGGUUCGGAGAATT-3'. Cells were plated into 6-well plates overnight, to reach 50-60\% confluency, and transfected with the BMI-1 siRNA/NC using Lipofectamine ${ }^{\circledR} 2000$ reagent (Invitrogen; Thermo Fisher Scientific, Inc.), according to the manufacturer's protocol. After $6 \mathrm{~h}$ of incubation with the transfection reagent and DNA, the cells were incubated in fresh supplemented medium for a further 24 or $48 \mathrm{~h}$.

Reverse transcription-quantitative PCR (RT-qPCR). Total RNA was extracted using TRIzol ${ }^{\circledR}$ (Invitrogen; Thermo Fisher Scientific, Inc.), treated with DNase I (Takara Bio, Inc.) to eliminate contaminating genomic DNA, and then reverse transcribed using a PrimeScript ${ }^{\mathrm{TM}}$ RT reagent kit (Perfect Real Time kit; Dalian Meilun Biology Technology Co., Ltd.). RT-qPCR was performed in a reaction volume of $20 \mu \mathrm{l}$ containing SYBR green PCR mix, according to the manufacturer's protocol. Each sample was run in triplicate. GAPDH 
A

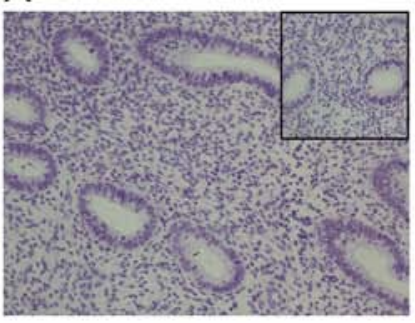

$E$

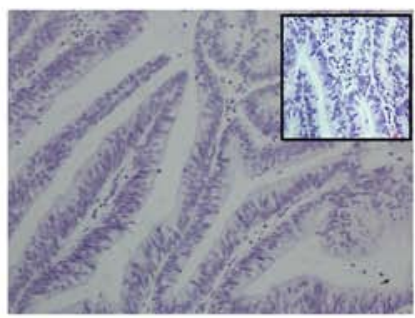

B

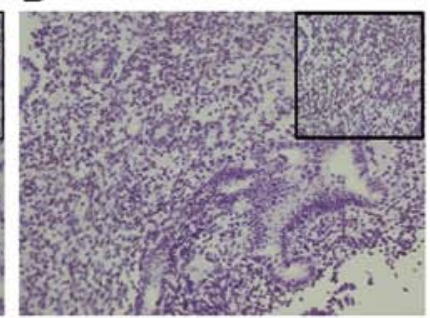

$\mathrm{F}$

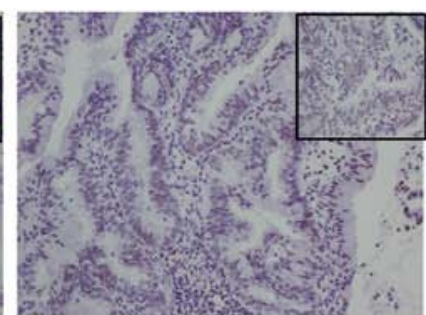

C

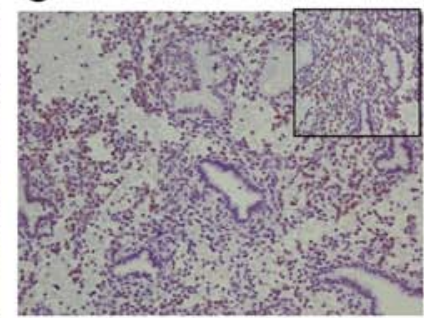

G

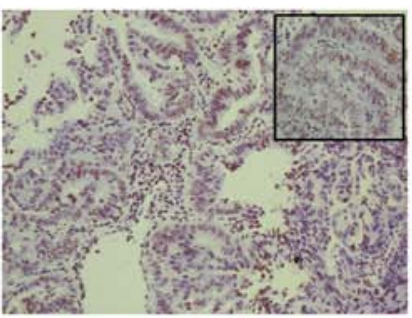

D

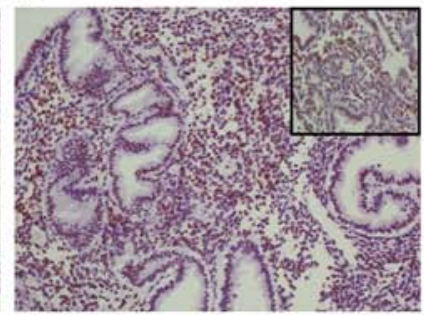

$\mathrm{H}$

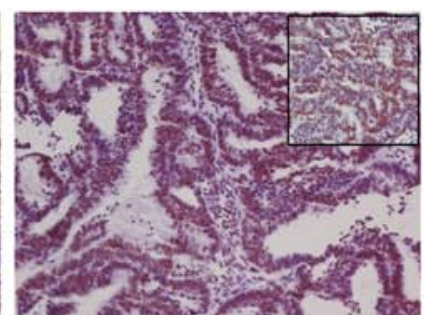

Figure 1. Representative examples of different BMI-1 expression levels in the normal endometrium and in endometrial adenocarcinoma. $(\mathrm{A})-,(\mathrm{B})+,(\mathrm{C})++$ and (D) +++ BMI-1 expression in normal endometrium. (E) -, (F) +, (G) ++ and (H) +++ BMI-1 expression in endometrial carcinoma. B-lymphoma Mo-MLV insertion region 1. Magnification, x200; inset magnification x400.

was used as the internal control, to which all samples were normalized. Results were calculated using the $2^{-\Delta \Delta C q}$ method (26). The primer sequences for BMI-1 and GAPDH used were: BMI-1 forward, TCATGGTCATCCTTCTGCTGA TGCTG and reverse, GCATGAGCATCACAGTCATTGCTG CT; and GAPDH forward, CATATGCAAGGTCATCCATGA CAACTTTG and reverse, AAGCTTGTCCACCACCCTGTT GCTGTAG.

MTT cell viability assay. A total of $2 \times 10^{3}$ cells were plated per well in $200 \mathrm{ml}$ medium in a 96 -well plate, with six wells per a group, and the cells were transfected with si-BMI-1 or negative control-siRNA as described above. After 24, 48, 72 or $96 \mathrm{~h}$, $20 \mu \mathrm{l} 1 \mathrm{mg} / \mathrm{ml}$ MTT solution (Sigma-Aldrich; Merck KGaA) was added to each well, and cells were incubated for a further $4 \mathrm{~h}$ at $37^{\circ} \mathrm{C}$ with $5 \% \mathrm{CO}_{2}$ and $95 \%$ air. Subsequently, the medium was removed, and the precipitated formazan was dissolved in $200 \mu \mathrm{l}$ DMSO. After agitation for $15 \mathrm{~min}$, the absorbance of the medium was measured at $495 \mathrm{~nm}$ using a microplate reader (Omega Bio-Tek, Inc.).

Transwell assays. Briefly, 24-well transwell chambers, with $8 \mu \mathrm{m}$ pores (Costar; Corning, Inc.) were used to assess the migratory and invasive properties. For the transwell migration assays, frozen Matrigel ${ }^{\circledR}$ (Corning, Inc.) was dissolved at room temperature and was diluted to a working solution of 1:8 Matrigel: Serum-free medium. The upper chambers were coated with $100 \mu \mathrm{l}$ Matrigel solution per well, and incubated for $24 \mathrm{~h}$ to allow the Matrigel to polymerize. For the invasion assays, the chambers were not coated prior to use. A total of $24 \mathrm{~h}$ after transfection, the cells were seeded in the upper chamber of the transwell inserts in $200 \mu \mathrm{l}$ serum-free medium $\left(1 \times 10^{5}\right.$ cells $\left./ \mathrm{ml}\right)$. After $24 \mathrm{~h}$ of incubation, cells which had not migrated or invaded were removed. The cells on the underside of the chambers were fixed using methanol and 3.7\% formaldehyde solution at room temperature, each for $5 \mathrm{~min}$. Subsequently, the cells were stained with $0.1 \%$ crystal violet at room temperature for $30 \mathrm{~min}$, imaged using an Olympus IX51 inverted microscope (Olympus Corporation) with a UIS2 optical system and phase contrast objectives, and the number of cells in five randomly chosen fields of view (magnification, x200) were counted. A total of three independent experiments were performed for statistical analysis.

Western blotting. After transfection for $48 \mathrm{~h}$, proteins were extracted, and western blotting was performed. Proteins were extracted using RIPA lysis buffer (Beyotime Institute of Biotechnology) with 1\% PMSF (Thermo Fisher Scientific Inc.) and $1 \% \mathrm{NaF}$ (Beyotime Institute of Biotechnology). Protein concentrations were determined using a bicinchoninic acid protein assay kit (Beyotime Institute of Biotechnology). A total of $40 \mathrm{mg}$ of protein was loaded per lane on $10 \%$ SDS-gel, resolved by SDS-PAGE and subsequently transferred to a PVDF membrane. Membranes were blocked with $5 \%$ fat-free dry milk at room temperature for $2 \mathrm{~h}$, followed by incubation with primary rabbit anti-BMI-1 monoclonal antibodies (1:1,000 dilution; cat. no. ab126738; Abcam), and rabbit monoclonal antibodies against E-cadherin, $\mathrm{N}$-cadherin, vimentin, Keratin and slug (1:1,000 dilution; cat. nos. 3195, 4061, 5741s, 4546p and 58613, respectively; Cell Signaling Technology, Inc.) overnight at $4^{\circ} \mathrm{C}$. After washing with TBS-Tween three times 5 min each, the membranes were incubated with secondary goat anti-rabbit IgG antibody conjugated to horseradish peroxidase (1:5,000; cat. nos. ab6721; Abcam) for $2 \mathrm{~h}$ at room temperature. GAPDH was used as the loading control with a rabbit anti-GAPDH antibody (1:1,000; cat. no. cst2118; Cell Signaling Technology, Inc.) overnight at $4^{\circ} \mathrm{C}$. Densitometry analysis was performed using ImageJ software version 1.46 (National Institutes of Health). A total of three independent experiments were performed for statistical analysis. 
Table I. BMI-1 expression between normal endometrial and endometrial adenocarcinoma tissues.

\begin{tabular}{lc}
\hline Group & $\mathrm{n}(\%$ of total $)$ \\
\hline Normal endometrium & 40 \\
Low BMI-1 expression & $36(90 \%)$ \\
High BMI-1 expression & $4(10 \%)$ \\
Endometrial adenocarcinoma & 60 \\
Low BMI-1 expression & $24(40.0 \%)$ \\
High BMI-1 expression & $36(60.0 \%)$
\end{tabular}

BMI-1, B-lymphoma Mo-MLV insertion region 1.

Statistical analysis. Experiments were performed at least three times for statistical analysis. SPSS version 23.0 (IBM Corp.) and GraphPad version 6.0 (GraphPad Software, Inc.) were used for statistical analysis. Results are presented as the mean \pm standard error of the mean. Comparison among groups was performed using a one-way ANOVA with a post hoc Tukey's test for multiple comparisons. Unpaired nominal-scale data was analyzed using a $\chi^{2}$ test. Pearson's correlation coefficient tests were used to analyze the correlation between BMI-1 expression and the clinicopathological parameters. A log-rank test was used for Kaplan-Meier survival analysis. The significance of the clinicopathological characteristics on survival were analyzed using a Cox proportional hazards model in univariate and multivariate analysis. $\mathrm{P}<0.05$ was considered to indicate a statistically significant difference.

\section{Results}

Expression of BMI-1 in endometrial adenocarcinoma tissues. IHC was performed to detect BMI-1 expression levels in endometrial adenocarcinoma and normal endometrial tissues. BMI-1 expression levels were significantly increased in endometrial adenocarcinoma tissues compared with the normal endometrial tissue $\left(\chi^{2}=25.0, \mathrm{P}<0.001\right)$. A total of $10 \%$ (4/40) of normal endometrial tissues exhibited high expression of BMI-1 (representative example in Fig. 1C and D), and the remaining tissues (90\%, 36/40) had no or low expression levels of BMI-1 (representative example in Fig. 1A and B). However, 60\% (36/60) of the cancer tissues exhibited high BMI-1 expression levels (representative example in Fig. $1 \mathrm{G}$ and $\mathrm{H}$ ) and the remainder $(40 \%, 24 / 60)$ exhibited low expression (representative example in Fig. 1E and F). The intensity of staining observed in endometrial adenocarcinoma tissue was higher compared with the normal endometrial tissue (Table II). Interestingly, BMI-1 expression was detected in both the nucleus and cytoplasm in normal and cancer cells (Fig. 1C, D, G and H). These results suggest that BMI-1 expression is increased in endometrial adenocarcinoma tissues compared with normal endometrial tissues (Table I).

Association between BMI-1 expression and clinicopathological characteristics of endometrial adenocarcinoma.
The possible correlations between BMI-1 expression and clinicopathological characteristics were assessed. As shown in Tables II and III, BMI-1 expression levels were correlated with the FIGO stage, myometrial invasion and lymph node metastasis $(\mathrm{P}<0.05)$. However, there was no correlation between BMI-1 expression levels and age or grade.

High BMI-1 expression is associated with a less favorable prognosis. As shown in Table IV, in the 120-month follow-up study, Kaplan-Meier analyses showed that 36 patients with high expression levels of BMI-1 had a survival rate of $52.8 \%$ and 24 patients with low expression levels of BMI-1 had a survival rate of $91.7 \%$. There was a significant difference in survival rate in patients with endometrial adenocarcinoma with high and low expression levels of BMI-1 $(\mathrm{P}=0.040$, $\mathrm{HR}=1.596$ ). Kaplan-Meier analyses revealed that the overall survival time of patients with high expression levels of BMI-1 was significantly shorter compared with patients with low expression levels (Fig. 2).

Cox regression proportional hazard analyses were used to determine the risk factors associated with death. As shown in Table V, univariate Cox regression analyses revealed that the risk of death with high BMI-1 expression levels was significantly increased compared with low BMI-1 expression levels in patients with endometrial adenocarcinoma $(\mathrm{P}=0.040$, $\mathrm{HR}=1.596$ ). Additionally, late-stage (III, $\mathrm{P}=0.006, \mathrm{HR}=1.67$ ), myometrial invasion $(\mathrm{P}=0.006, \mathrm{HR}=1.509)$ and lymph node metastasis $(\mathrm{P}=0.004, \mathrm{HR}=1.703)$ were also significantly associated with less favorable prognosis. However, a high grade was not associated with increased risk of death $(\mathrm{P}=0.234)$. After adjustment for confounding factors, BMI-1 expression levels were still shown to predict a less favorable prognosis using multivariate Cox regression analysis $(\mathrm{P}=0.037, \mathrm{HR}=1.698$; Table VI). Furthermore, late-stage $(\mathrm{P}=0.017, \mathrm{HR}=1.645)$, myometrial invasion $(\mathrm{P}=0.010, \mathrm{HR}=1.305)$ and lymph node metastasis $(\mathrm{P}=0.016, \mathrm{HR}=1.352$; Table $\mathrm{VI})$ were still shown to predict a less favorable prognosis.

Knockdown of BMI-1 expression in-vitro reduces endometrial adenocarcinoma cell growth and proliferation. To determine the potential functional roles of BMI-1 in the Ishikawa and JEC endometrial cancer cell lines, si-BMI-1 was transfected into cells to knockdown the expression levels of BMI-1, and RT-qPCR was used to assess the transfection efficiency. The results showed that the quantitative expression of BMI-1 mRNA decreased $37.45 \pm 2.7 \%$ in Ishikawa cells and $39.95 \pm 5.0 \%$ in JEC cells following si-BMI-1 transfection (Fig. 3).

The MTT assay results showed that cell growth and proliferation were decreased in the si-BMI-1 transfected Ishikawa and JEC cells compared with the respective controls (Fig. 4).

Knockdown of BMI-1 expression decreases migration and invasion of Ishikawa and JEC cells. After the cells were transfected with si-BMI-1, the effects of BMI-1 on cell migration and invasion were assessed using transwell assays. The results showed that knockdown of BMI-1 expression significantly reduced the migratory and invasive capacities of Ishikawa (Fig. 5A and B) and JEC cells (Fig. 5C and D; $\mathrm{P}<0.001)$. 
Table II. Patient characteristics and percentage of positive cells and staining intensity of BMI-1 expression.

\begin{tabular}{|c|c|c|c|c|c|c|c|c|c|c|}
\hline \multirow[b]{2}{*}{ Characteristics } & \multirow[b]{2}{*}{$\mathrm{n}$} & \multicolumn{5}{|c|}{ Proportion of stained cells, n (\%) } & \multicolumn{4}{|c|}{ Staining intensity, $\mathrm{n}$} \\
\hline & & 0 & 1 & 2 & 3 & 4 & 0 & 1 & 2 & 3 \\
\hline \multicolumn{11}{|l|}{ Age } \\
\hline$\leq 60$ & 21 & $1(2.0)$ & $2(18.5)$ & $4(34.6)$ & $7(68.2)$ & 7 (89.6) & 1 & 2 & 4 & 14 \\
\hline$>60$ & 39 & $1(3.6)$ & $3(21.4)$ & $5(40.2)$ & $10(60.6)$ & $20(92.5)$ & 1 & 4 & 11 & 23 \\
\hline \multicolumn{11}{|l|}{ FIGO stage } \\
\hline I & 26 & $1(2.8)$ & $5(15.6)$ & $5(32.5)$ & $7(71.5)$ & $8(84.2)$ & 1 & 8 & 10 & 7 \\
\hline II & 20 & $1(3.2)$ & $3(16.5)$ & $6(38.2)$ & $5(78.6)$ & $5(89.7)$ & 1 & 4 & 5 & 10 \\
\hline III & 14 & 0 & $1(19.3)$ & 0 & $1(64.0)$ & $12(91.4)$ & 0 & 0 & 6 & 8 \\
\hline \multicolumn{11}{|l|}{ Histologic type } \\
\hline Endometrioid-adenocarcinoma & 29 & $1(3.0)$ & $3(15.2)$ & $4(33.2)$ & $10(79.4)$ & $11(86.7)$ & 1 & 6 & 12 & 10 \\
\hline Serous-adenocarcinoma & 31 & $1(3.5)$ & $3(17.5)$ & $7(38.0)$ & $8(79.2)$ & $12(89.6)$ & 1 & 4 & 10 & 16 \\
\hline \multicolumn{11}{|l|}{ Grade } \\
\hline G1 & 28 & $1(3.2)$ & $3(14.8)$ & $6(36.0)$ & $8(78.2)$ & $10(88.5)$ & 1 & 6 & 12 & 9 \\
\hline G2 & 18 & $1(3.5)$ & $2(16.6)$ & $5(36.5)$ & $5(78.6)$ & $5(88.5)$ & 1 & 4 & 5 & 8 \\
\hline G3 & 14 & $1(3.6)$ & $1(20.8)$ & $2(37.6)$ & $4(62.5)$ & $6(91.8)$ & 1 & 1 & 3 & c \\
\hline \multicolumn{11}{|l|}{ Myometrial invasion } \\
\hline$<50 \%$ & 45 & $2(2.8)$ & $4(20.6)$ & $8(40.1)$ & $15(64.8)$ & $16(90.7)$ & 2 & 12 & 8 & 23 \\
\hline$\geq 50 \%$ & 15 & 0 & $1(22.3)$ & $1(35.7)$ & $1(64.0)$ & $12(91.4)$ & 0 & 0 & 5 & 10 \\
\hline \multicolumn{11}{|l|}{ Lymph node metastasis } \\
\hline No & 47 & $2(2.8)$ & $5(19.9)$ & $9(37.4)$ & $13(63.2)$ & $18(91.1)$ & 2 & 11 & 10 & 24 \\
\hline Yes & 13 & 0 & 0 & $1(39.7)$ & $2(65.6)$ & $10(91.2)$ & 0 & 0 & 3 & 10 \\
\hline
\end{tabular}

BMI-1, B-lymphoma Mo-MLV insertion region 1; FIGO, International Federation of Gynecology and Obstetrics staging system.

Table III. Correlation between BMI-1 expression and clinicopathological characteristics in patients with endometrial adenocarcinoma.

\begin{tabular}{|c|c|c|c|c|c|}
\hline $\begin{array}{l}\text { Clinicopathological } \\
\text { characteristics }\end{array}$ & $\mathrm{n}$ & $\begin{array}{c}\text { Low BMI-1 } \\
\text { expression (\%) }\end{array}$ & $\begin{array}{l}\text { High BMI-1 } \\
\text { expression (\%) }\end{array}$ & $\begin{array}{l}\text { Correlation } \\
\text { coefficient }\end{array}$ & P-value \\
\hline Age & & & & 0.100 & 0.448 \\
\hline$\leq 60$ & 21 & $7(33.33)$ & $14(66.67)$ & & \\
\hline$>60$ & 39 & $17(43.59)$ & $22(56.41)$ & & \\
\hline FIGO stage & & & & 0.290 & $0.025^{\mathrm{a}}$ \\
\hline I-II & 46 & $22(47.83)$ & $24(52.17)$ & & \\
\hline III & 14 & $2(14.29)$ & $12(85.71)$ & & \\
\hline Grade & & & & 0.048 & 0.714 \\
\hline G1/G2 & 46 & $19(41.30)$ & $27(58.70)$ & & \\
\hline G3 & 14 & $5(35.71)$ & $9(64.29)$ & & \\
\hline Myometrial invasion & & & & 0.314 & $0.014^{\mathrm{a}}$ \\
\hline$<50 \%$ & 45 & $22(48.89)$ & $23(51.11)$ & & \\
\hline$\geq 50 \%$ & 15 & $2(13.3)$ & $13(86.67)$ & & \\
\hline Lymph node metastasis & & & & 0.347 & $0.007^{\mathrm{b}}$ \\
\hline No & 47 & $23(48.94)$ & $24(51.06)$ & & \\
\hline Yes & 13 & $1(7.69)$ & $12(92.31)$ & & \\
\hline
\end{tabular}

${ }^{\mathrm{a}} \mathrm{P}<0.05,{ }^{\mathrm{b}} \mathrm{P}<0.01$. BMI-1, B-lymphoma Mo-MLV insertion region 1; FIGO, International Federation of Gynecology and Obstetrics staging system. 
Table IV. Kaplan-Meier analyses of the association between BMI-1 expression and survival time.

\begin{tabular}{lccc}
\hline BMI-1 expression & Survival rate $(\%)$ & $95 \%$ confidence interval & $\chi^{2}$ \\
\hline Low & 91.7 & $115.365-121.051$ & 12.036 \\
High & 52.8 & $87.564-107.007$ & $<0.001$
\end{tabular}

BMI-1, B-lymphoma Mo-MLV insertion region 1.

Table V. Univariate Cox-regression analysis of clinicopathological characteristics in patients with endometrial adenocarcinoma.

\begin{tabular}{|c|c|c|c|}
\hline Clinicopathological characteristics & $95 \%$ Confidence interval & P-value & Hazard ratio \\
\hline $\begin{array}{l}\text { Age } \\
\leq 60 \\
>60\end{array}$ & $0.173-1.482$ & 0.214 & -0.680 \\
\hline $\begin{array}{l}\text { FIGO stage } \\
\text { I-II } \\
\text { III }\end{array}$ & $1.598-7.66$ & $0.006^{\mathrm{b}}$ & 1.670 \\
\hline $\begin{array}{l}\text { Grade } \\
\text { G1/G2 } \\
\text { G3 }\end{array}$ & $0.597-8.244$ & 0.234 & 0.797 \\
\hline $\begin{array}{l}\text { Myometrial invasion } \\
<50 \% \\
\geq 50 \%\end{array}$ & $1.547-3.228$ & $0.006^{\mathrm{b}}$ & 1.509 \\
\hline $\begin{array}{l}\text { Lymph node metastasis } \\
\text { No } \\
\text { Yes }\end{array}$ & $1.750-7.236$ & $0.004^{\mathrm{b}}$ & 1.703 \\
\hline $\begin{array}{l}\text { BMI-1 expression } \\
\text { Low } \\
\text { High }\end{array}$ & $1.076-2.617$ & $0.040^{\mathrm{a}}$ & 1.596 \\
\hline
\end{tabular}

${ }^{\mathrm{a}} \mathrm{P}<0.05,{ }^{\mathrm{b}} \mathrm{P}<0.01$. BMI-1, B-lymphoma Mo-MLV insertion region 1; FIGO, International Federation of Gynecology and Obstetrics staging system.

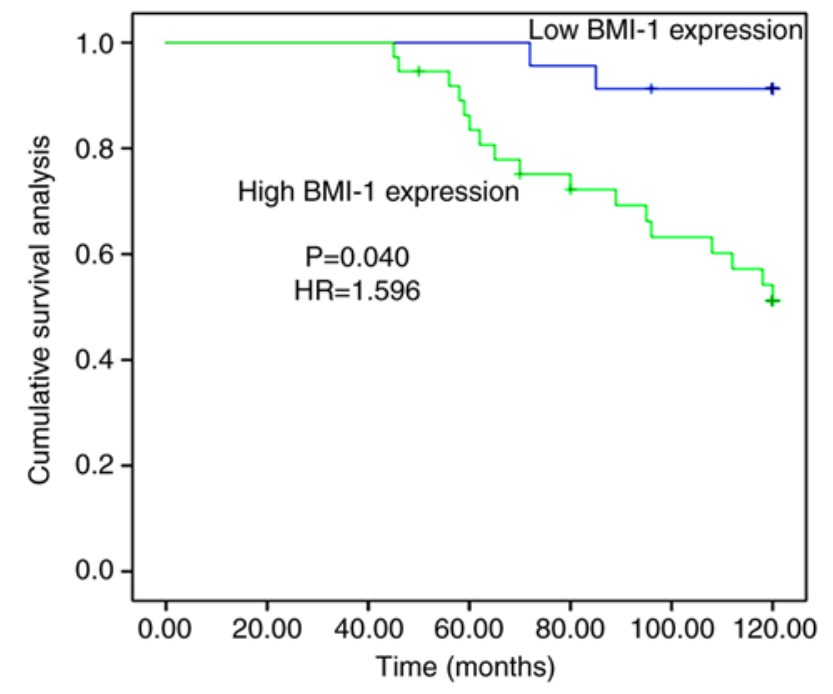

Figure 2. High expression of BMI-1 is associated with reduced survival times in patients with endometrial adenocarcinoma. BMI-1, B-lymphoma Mo-MLV insertion region 1.
Knockdown of BMI-1 expression inhibits EMT in Ishikawa and JEC cells. To further investigate the functional roles of BMI-1 expression on the migratory and invasive capacities of Ishikawa and JEC cells, the expression of EMT-associated proteins was assessed in cells transfected with si-BMI-1. Western blotting showed that the expression levels of the mesenchymal markers $\mathrm{N}$-cadherin, vimentin and the downstream EMT transcription factor, Slug, were decreased in the si-BMI-1 transfected cells, whereas the expression levels of the epithelial markers E-cadherin and keratin were increased relative to the respective control cells (Fig. 6).

\section{Discussion}

Endometrial adenocarcinoma is one of the most common gynecological malignancies in women and is prone to invade adjacent regions and to metastasize to lymph nodes (27-29). To develop effective treatments for treatment of endometrial 
Table VI. Multivariate Cox-regression analysis of clinicopathological characteristics in patients with endometrial adenocarcinoma.

\begin{tabular}{lcc}
\hline Clinicopathological characteristics & $95 \%$ Confidence interval & P-value \\
\hline FIGO stage & $1.515-6.217$ & 0.008 \\
I-II & & 1.601 \\
III & $1.365-9.967$ & 0.010 \\
Myometrial invasion & & 1.305 \\
$<50 \%$ & $1.290-5.579$ & 0.016 \\
$\geq 50 \%$ & & 1.352 \\
Lymph node metastasis & & 0.037 \\
No & $1.102-4.329$ & 1.645 \\
Yes & & \\
BMI-1 expression & & \\
Low & & \\
High & & \\
\hline
\end{tabular}

BMI-1, B-lymphoma Mo-MLV insertion region 1; FIGO, International Federation of Gynecology and Obstetrics staging system.
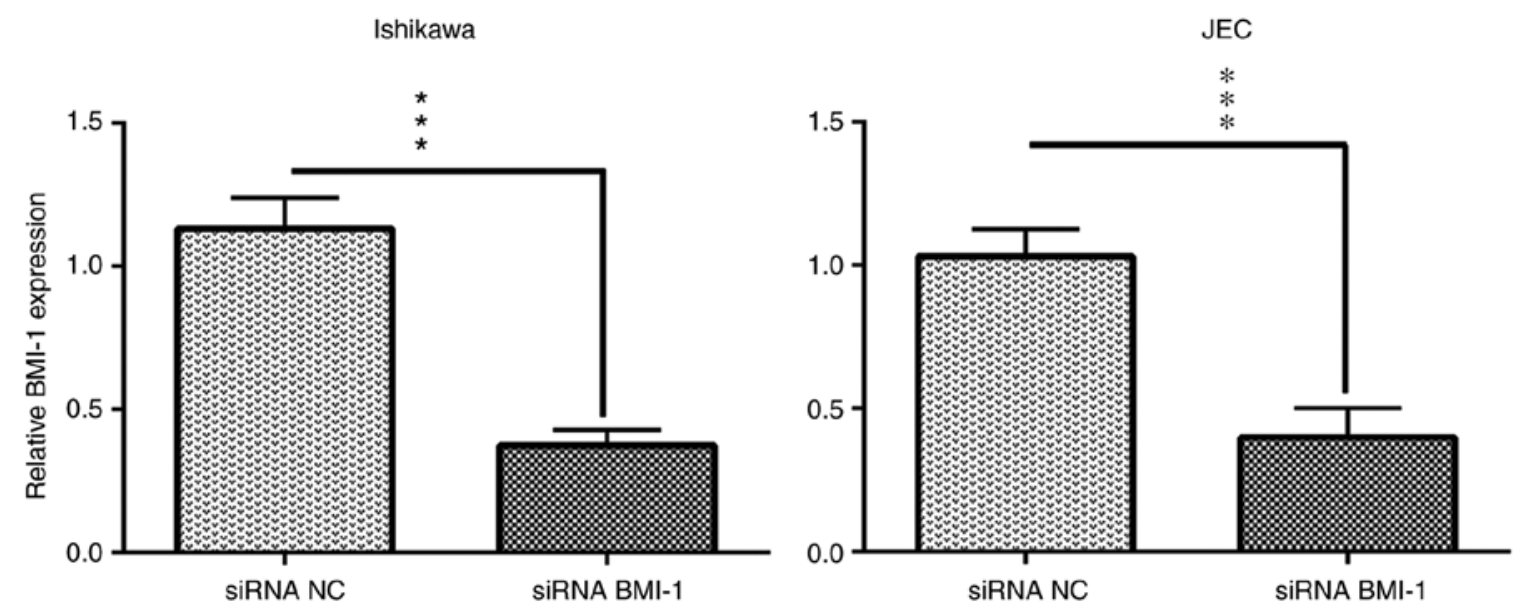

Figure 3. Efficiency of BMI-1 knockdown using si-BMI-1 in Ishikawa and JEC cells. ${ }^{* * *} \mathrm{P}<0.001$. BMI-1, B-lymphoma Mo-MLV insertion region 1; si-RNA, small interfering RNA; NC, negative control.
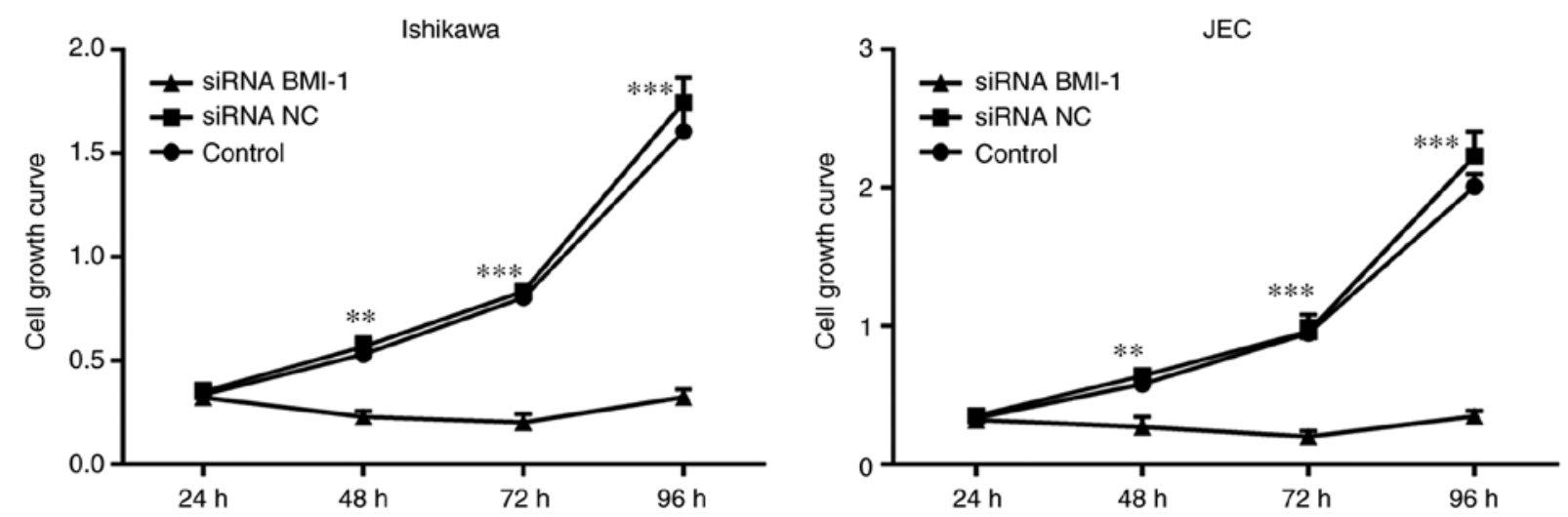

Figure 4. Growth curves of Ishikawa and JEC cells following knockdown of BMI-1. Knockdown of BMI-1 significantly reduced cell proliferation in both cell lines. ${ }^{* *} \mathrm{P}<0.01,{ }^{* * * *} \mathrm{P}<0.001$ vs. si-BMI-1. BMI-1, B-lymphoma Mo-MLV insertion region 1; si-RNA, small interfering RNA; NC, negative control.

adenocarcinoma, it is important to identify the factors underlying tumorigenesis, invasion and metastasis. One of the clinical features of endometrial adenocarcinoma is uterine bleeding $(30,31)$. Normal endometrium exhibits proliferative, 
A

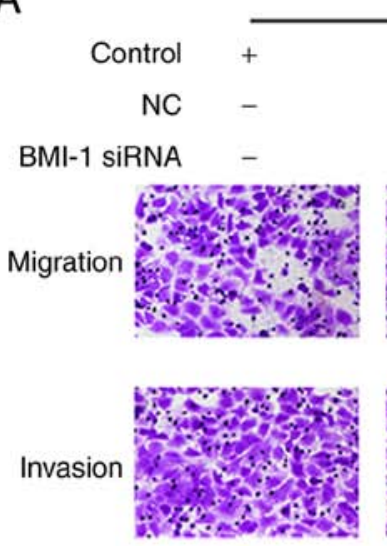

Ishikawa

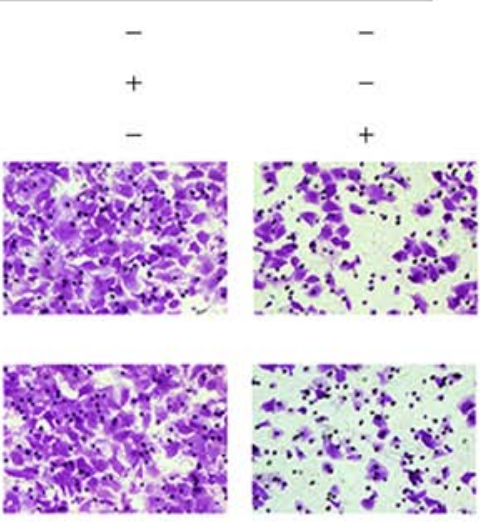

B

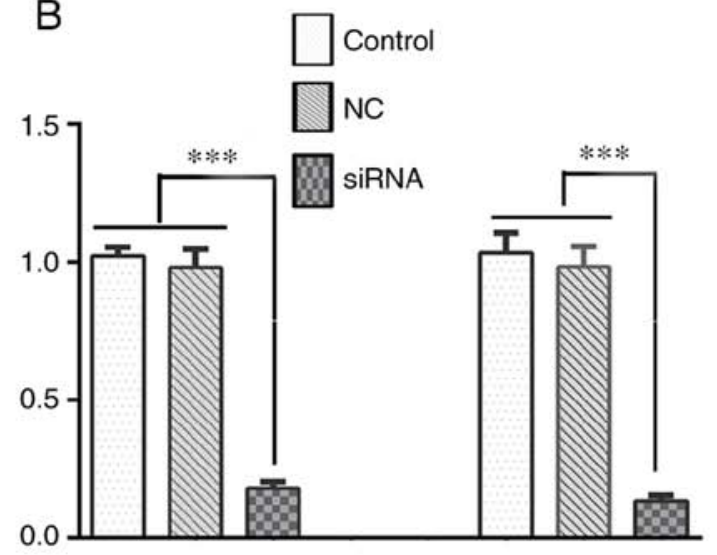

C
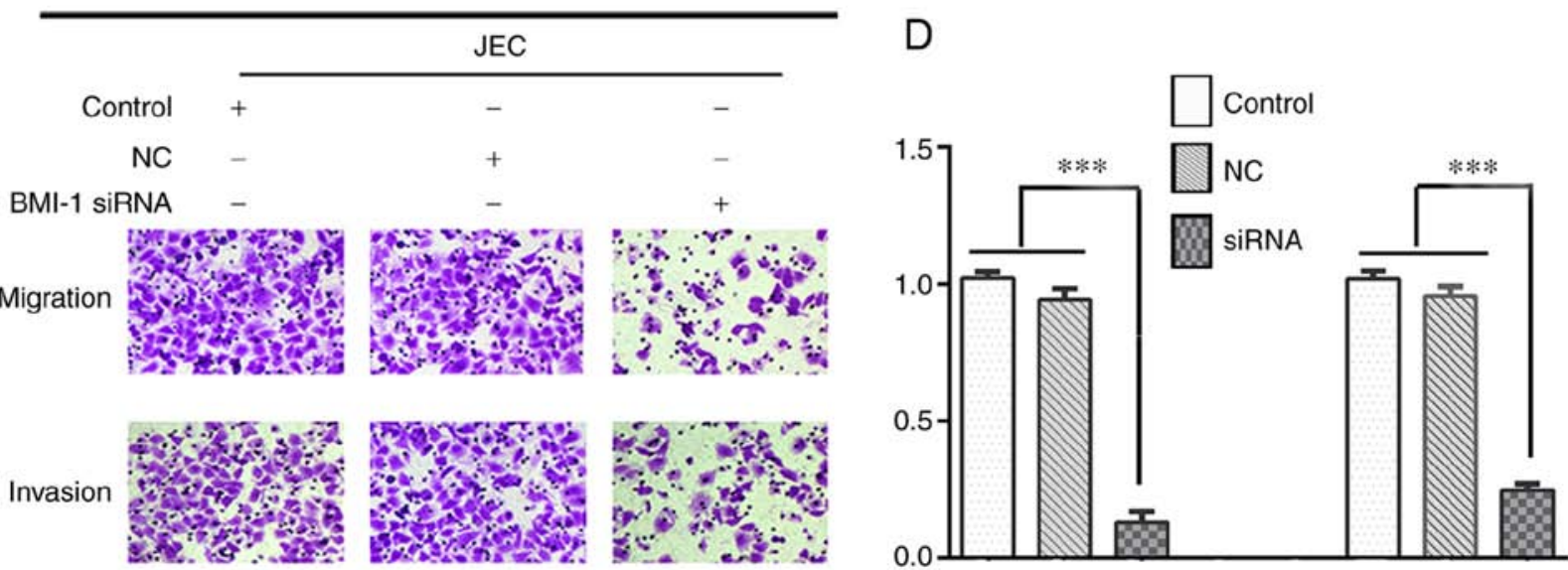

Figure 5. Effect of BMI-1 on migration and invasion of endometrial adenocarcinoma cells. (A) Representative images and (B) quantitative analysis of migration and invasion in Ishikawa cells. (C) Representative images and (D) quantitative analysis of migration and invasion in JEC cells. Magnification, $\mathrm{x} 200 .{ }^{* * *} \mathrm{P}<0.01$. BMI-1, B-lymphoma Mo-MLV insertion region 1; si-RNA, small interfering RNA; NC, negative control.

secretory and atrophic properties $(32,33)$. Therefore, patients with abnormal uterine bleeding who had undergone an endometrium biopsy $(34,35)$ where the results of pathological analysis showed proliferation or secretion were used as control group in the present study, and it was shown that BMI-1 expression was significantly higher in endometrial adenocarcinoma tissues compared with the control tissues. BMI-1 was demonstrated to serve an important functional role in the progression of endometrial adenocarcinoma. In endometrial adenocarcinoma tissues, $60 \%$ of tissues exhibited high levels of expression of BMI-1 in the present study, consistent with that of a previous study which found that BMI-1 expression was significantly upregulated in endometrial cancer (15). In the present study, high BMI-1 expression levels were correlated with myometrial invasion and lymph node metastasis. Of the samples classed as FIGO stage III, deep myometrial invasion and lymph nodes metastasis, $>85 \%$ exhibited high expression levels of BMI-1. These results showed that higher BMI-1 expression levels were associated with more aggressive behavior. A previous study also found that low BMI-1 expression levels were associated with histological grade 3 and deep myometrial infiltration (22). The difference in results between the present and previous studies may reflect differences in BMI-1 status of the samples used in the different studies, with tissue samples obtained from varying populations. In the present study, high BMI-1 expression levels were not correlated with tumor differentiation, suggesting that high BMI-1 expression levels were associated with tumor progression but not differentiation.

Upregulated expression of BMI-1 was a poor prognostic factor in patients with endometrial adenocarcinoma, consistent with previous studies $(16,18-21,36-38)$. In the present study, it was found that patients with high BMI-1 expression levels had a worse prognosis compared with patients with low BMI-1 expression levels. Late-stage, myometrial invasion and lymph node metastasis were also unfavorable prognostic factors. However, high expression levels of BMI-1 was an independent prognostic indicator, alongside late-stage, myometrial invasion and lymph node metastasis.

Invasion and metastasis of cancer is commonly associated with a poor prognosis in patients $(27,39,40)$. Knockdown of BMI-1 expression levels reduced the proliferative, migratory and invasive capacities of Ishikawa and JEC cells. EMT is characterized by a loss of the epithelial markers E-cadherin and keratin, and increased the expression levels of the mesenchymal markers vimentin and $\mathrm{N}$-cadherin (41-46). There was also activation of the EMT related pathways, leading to an increase in migratory and invasive behavior (43). The BMI-1 gene has been reported to stimulate EMT by reducing 


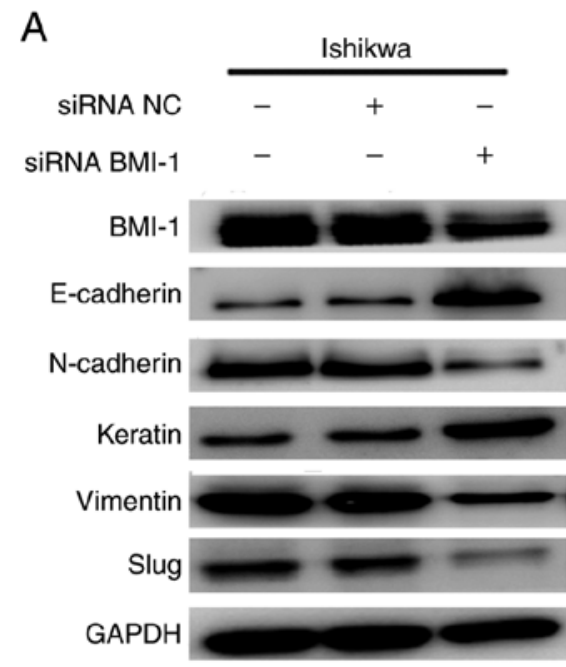

C

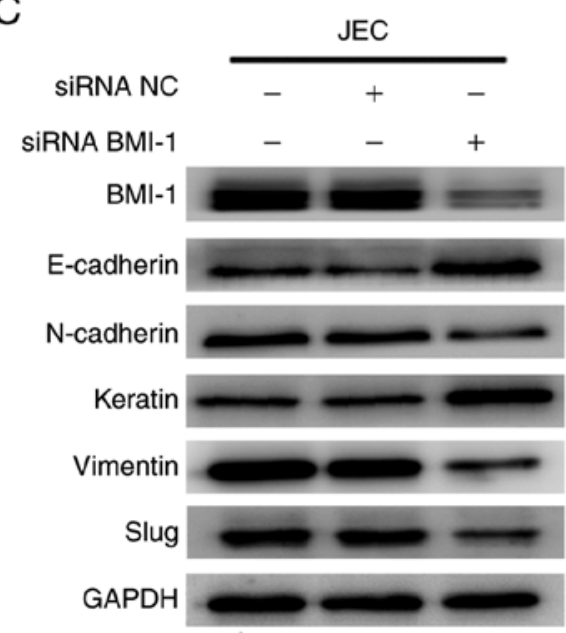

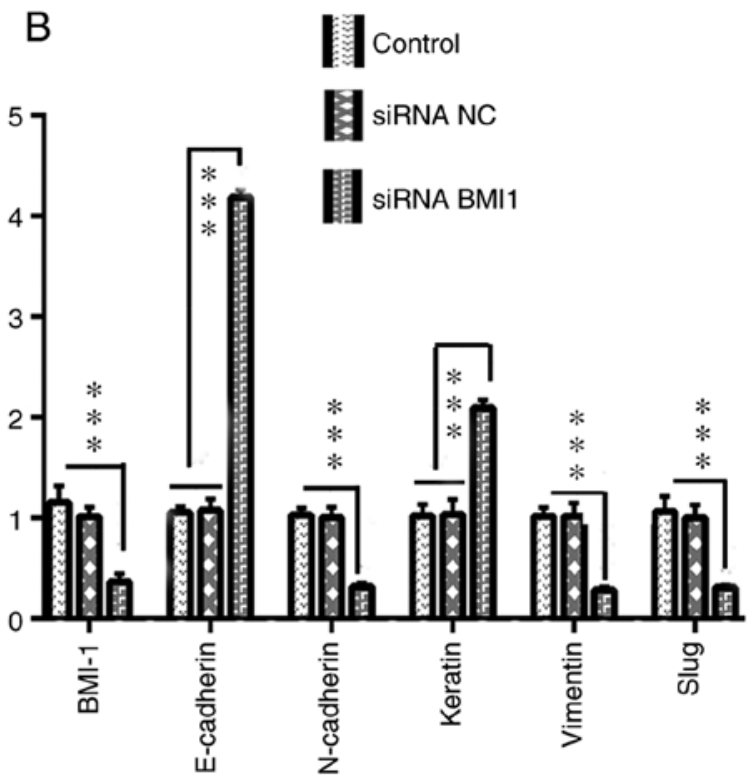

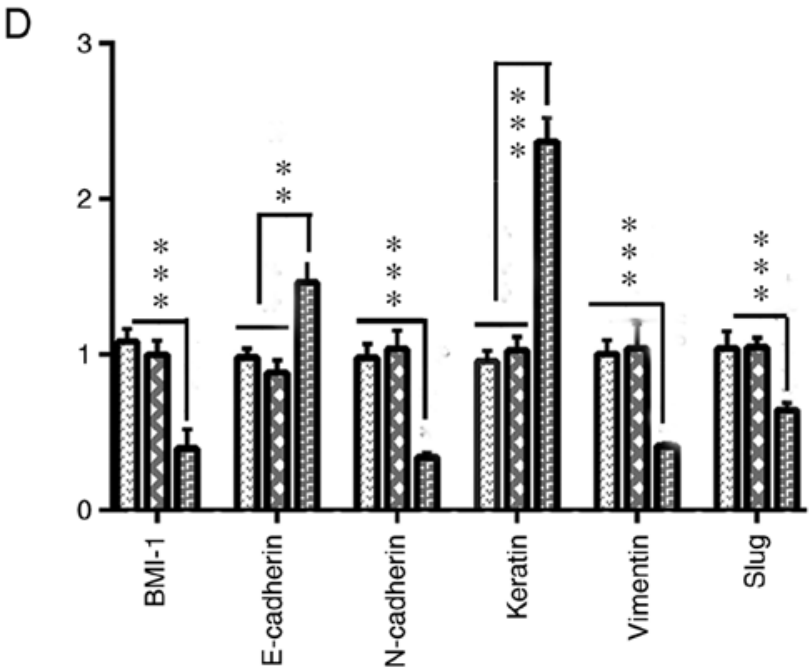

Figure 6. Knockdown of BMI-1 inhibits EMT in Ishikawa and JEC cells. (A) Representative blots and (B) quantitative analysis of the protein expression levels of EMT-associated proteins and BMI-1 in Ishikawa cells transfected with si-BMI-1. (C) Representative blots and (D) quantitative analysis of the protein expression levels of EMT-associated proteins and BMI-1 in JEC cells transfected with si-BMI-1. ${ }^{* * *} \mathrm{P}<0.01,{ }^{* * *} \mathrm{P}<0.001$ vs. si-BMI-1. BMI-1, B-lymphoma Mo-MLV insertion region 1; si-RNA, small interfering RNA; NC, negative control.

the expression levels of the epithelial marker E-cadherin, and increasing expression of the mesenchymal marker, $\mathrm{N}$-cadherin $(16,17,47-52)$. In the present study, western blotting showed that knockdown of BMI-1 expression was associated with increased E-cadherin and keratin expression, whilst simultaneously reducing $\mathrm{N}$-cadherin, vimentin and Slug expression levels. These results are consistent with the results of previous study $(17,23)$. One limitation of the present study is that the expression and function of BMI-1 in normal endometrial cells were not determined and compared with endometrial adenocarcinoma cells.

In conclusion, the present study showed that BMI-1 expression was increased in endometrial adenocarcinoma tissues compared with the control tissues, and that knockdown of BMI-1 expression may inhibit EMT in endometrial adenocarcinoma cells. Additionally, BMI-1 expression was correlated with tumor invasion and metastasis, contributing to lymph node metastases and deep myometrial invasion in endometrial adenocarcinoma. These results suggest that BMI-1 may serve as a potential target for treatment of endometrial adenocarcinoma. However the mechanisms underlying the development of endometrial adenocarcinoma development are complex and require further study.

\section{Acknowledgements}

We appreciate the valuable work carried out by Dr Yu Yunliang (Binzhou Medical University) for her interpretation of the immunohistochemistry staining.

\section{Funding}

The present study was supportedby grants from theKey Research Items of Shandong Province (grant no. 2018GSF118190) and Science and Technology Planning Project of Yantai (grant no. 2018SFGY100). 


\section{Availability of data and materials}

The datasets used and/or analyzed during the present study are available from the corresponding author on reasonable request.

\section{Authors' contributions}

FL, LL and GL designed the study. JY, LC, ZB and YL performed the experiments and analyzed the data. FL wrote the manuscript. LL and GL revised the manuscript. All authors read and approved the final version of the manuscript.

\section{Ethics approval and consent to participate}

This study was approved by the Ethics Committee of the Yantai Affiliated Hospital of Binzhou Medical University (approval no. 2018-016) and the study adhered to the principles of the Declaration of Helsinki. Informed consent was obtained from each patient prior to tissue collection.

\section{Patient consent for publication}

Not applicable.

\section{Competing interests}

The authors declare that they have no competing interests.

\section{References}

1. Sheikh MA, Althouse AD, Freese KE, Soisson S, Edwards RP, Welburn S, Sukumvanich P, Comerci J, Kelley J, LaPorte RE and Linkov F: USA endometrial cancer projections to 2030: Should we be concerned? Future Oncol 10: 2561-2568, 2014.

2. Siegel RL, Miller KD and Jemal A: Cancer statistics, 2019. CA Cancer J Clin 69: 7-34, 2019.

3. Kulhan M, Kulhan G, Nayki U, Nayki C, Ulug P, Sipahi M and Yildirim Y: Assessment of clinicopathological features, evaluation of treatment, and prognosis of clear cell and serous papillary endometrial carcinoma. Ginekol Pol 87: 570-574, 2016.

4. Dessai SB, Adrash D, Geetha M, Arvind S, Bipin J, Nayanar S, Sachin K, Biji MS and Balasubramanian S: Pattern of care in operable endometrial cancer treated at a rural-based tertiary care cancer center. Indian J Cancer 53: 416-419, 2016.

5. Ouldamer L, Bendifallah S, Body G, Touboul C, Graesslin O, Raimond E, Collinet P, Coutant C, Bricou A, Lavoué V, et al: Incidence, patterns and prognosis of first distant recurrence after surgically treated early stage endometrial cancer: Results from the multicentre FRANCOGYN study group. Eur J Surg Oncol 45: 672-678, 2019.

6. Francis SR, Ager BJ, Do OA, Huang YJ, Soisson AP, Dodson MK, Werner TL, Sause WT, Grant JD and Gaffney DK: Recurrent early stage endometrial cancer: Patterns of recurrence and results of salvage therapy. Gynecol Oncol 154: 38-44, 2019.

7. Bogani G, Dowdy SC, Cliby WA, Ghezzi F, Rossetti D, Frigerio L and Mariani A: Management of endometrial cancer: Issues and controversies. Eur J Gynaecol Oncol 37: 6-12, 2016.

8. Evans T, Sany O, Pearmain P, Ganesan R, Blann A and Sundar S: Differential trends in the rising incidence of endometrial cancer by type: data from a UK population-based registry from 1994 to 2006. Br J Cancer 104: 1505-1510, 2011.

9. Rajasekhar VK and Begemann M: Concise review: Roles of polycomb group proteins in development and disease: A stem cell perspective. Stem Cells 25: 2498-2510, 2007.

10. Jiang L, Li J and Song L: Bmi-1, stem cells and cancer. Acta Biochim Biophys Sin (Shanghai) 41: 527-534, 2009.
11. Beà S, Tort F, Pinyol M, Puig X, Hernández L, Hernández S, Fernandez PL, van Lohuizen M, Colomer D and Campo E: BMI-1 gene amplification and overexpression in hematological malignancies occur mainly in mantle cell lymphomas. Cancer Res 61: 2409-2412, 2001.

12. Kim JH, Yoon SY, Jeong SH, Kim SY, Moon SK, Joo JH, Lee Y, Choe IS and Kim JW: Overexpression of Bmi-1 oncoprotein correlates with axillary lymph node metastases in invasive ductal breast cancer. Breast 13: 383-388, 2004.

13. Wang H, Pan K, Zhang HK, Weng DS, Zhou J, Li JJ, Huang W, Song HF, Chen MS and Xia JC: Increased polycomb-group oncogene Bmi-1 expression correlates with poor prognosis in hepatocellular carcinoma. J Cancer Res Clin Oncol 134: 535-541, 2008.

14. Zhang X, Wang CX, Zhu CB, Zhang J, Kan SF, Du LT, Li W, Wang LL and Wang S: Overexpression of Bmi-1 in uterine cervical cancer: Correlation with clinicopathology and prognosis. Int J Gynecol Cancer 20: 1597-1603, 2010.

15. Honig A, Weidler C, Häusler S, Krockenberger M, Buchholz S, Köster F, Segerer SE, Dietl J and Engel JB: Overexpression of polycomb protein BMI-1 in human specimens of breast, ovarian, endometrial and cervical cancer. Anticancer Res 30: 1559-1564, 2010.

16. Guo BH, Feng Y, Zhang R, Xu LH, Li MZ, Kung HF, Song LB and Zeng MS: Bmi-1 promotes invasion and metastasis, and its elevated expression is correlated with an advanced stage of breast cancer. Mol Cancer 10: 10, 2011.

17. Yuan W, Yuan Y, Zhang T and Wu S: Role of Bmi-1 in regulation of ionizing irradiation-induced epithelial-mesenchymal transition and migration of breast cancer cells. PLoS One 10: e0118799, 2015.

18. Wang MC, Jiao M, Wu T, Jing L, Cui J, Guo H, Tian T, Ruan ZP, Wei YC, Jiang LL, et al: Polycomb complex protein BMI-1 promotes invasion and metastasis of pancreatic cancer stem cells by activating PI3K/AKT signaling, an ex vivo, in vitro, and in vivo study. Oncotarget 7: 9586-9599, 2016.

19. Silva J, García V, García JM, Peña C, Domínguez G, Díaz R, Lorenzo Y, Hurtado A, Sánchez A and Bonilla F: Circulating Bmi-1 mRNA as a possible prognostic factor for advanced breast cancer patients. Breast Cancer Res 9: R55, 2007.

20. Abe S, Yamashita SI, Miyahara SO, Wakahara J, Yamamoto L, Mori R, Imamura N, Yoshida Y, Waseda R, Hiratsuka M, et al: Prognostic significance of BMI-1 But Not MEL-18 expression in pulmonary squamous cell carcinoma. Anticancer Res 37: 1923-1929, 2017.

21. Zhang X, Tian T, Sun W, Liu C and Fang X: Bmi-1 overexpression as an efficient prognostic marker in patients with nonsmall cell lung cancer. Medicine (Baltimore) 96: e7346, 2017.

22. Engelsen IB, Mannelqvist M, Stefansson IM, Carter SL, Beroukhim R, Øyan AM, Otte AP, Kalland KH, Akslen LA and Salvesen HB: Low BMI-1 expression is associated with an activated BMI-1-driven signature, vascular invasion, and hormone receptor loss in endometrial carcinoma. Br J Cancer 98: 1662-1669, 2008.

23. Li F, Liang A, Lv Y, Liu G, Jiang A and Liu P: MicroRNA-200c inhibits epithelial-mesenchymal transition by targeting the BMI-1 gene through the Phospho-AKT pathway in endometrial carcinoma cells in vitro. Med Sci Monit 23: 5139-5149, 2017.

24. FIGO Committee on Gynecologic Oncology: FIGO staging for carcinoma of the vulva, cervix, and corpus uteri. Int J Gynaecol Obstet 125: 97-98, 2014.

25. Hellmann F, Verdi M, Schlemper BR Jr and Caponi S: 50th anniversary of the Declaration of Helsinki: The double standard was introduced. Arch Med Res 45: 600-601, 2014.

26. Livak KJ and Schmittgen TD: Analysis of relative gene expression data using real-time quantitative PCR and the 2(-Delta Delta C(T)) method. Methods 25: 402-408, 2001.

27. Makker A and Goel MM: Tumor progression, metastasis, and modulators of epithelial-mesenchymal transition in endometrioid endometrial carcinoma: An update. Endocr Relat Cancer 23: R85-R111, 2016.

28. Mahdi H, Jernigan A, Nutter B, Michener C and Rose PG: Lymph node metastasis and pattern of recurrence in clinically early stage endometrial cancer with positive lymphovascular space invasion. J Gynecol Oncol 26: 208-213, 2015.

29. Devis L, Moiola CP, Masia N, Martinez-Garcia E, Santacana M, Stirbat TV, Brochard-Wyart F, García Á, Alameda F, Cabrera S, et al: Activated leukocyte cell adhesion molecule (ALCAM) is a marker of recurrence and promotes cell migration, invasion, and metastasis in early-stage endometrioid endometrial cancer. J Pathol 241: 475-487, 2017. 
30. Giannella L, Cerami LB, Setti T, Bergamini E and Boselli F: Prediction of endometrial hyperplasia and cancer among premenopausal Women with abnormal uterine bleeding. Biomed Res Int 2019: 8598152, 2019.

31. Khafaga A and Goldstein SR: Abnormal uterine bleeding. Obstet Gynecol Clin North Am 46: 595-605, 2019.

32. Goldstein SR and Lumsden MA: Abnormal uterine bleeding in perimenopause. Climacteric 20: 414-420, 2017.

33. Munro MG, Critchley HOD and Fraser IS; FIGO Menstrual Disorders Committee: The two FIGO systems for normal and abnormal uterine bleeding symptoms and classification of causes of abnormal uterine bleeding in the reproductive years: 2018 revisions. Int J Gynaecol Obstet 143: 393-408, 2018.

34. Stovall TG, Photopulos GJ, Poston WM, Ling FW and Sandlers LG: Pipelle endometrial sampling in patients with known endometrial carcinoma. Obstet Gynecol 77: 954-959, 1991.

35. Guido RS, Kanbour-Shakir A, Rulin MC and Christopherson WA: Pipelle endometrial sampling. Sensitivity in the detection of endometrial cancer. J Reprod Med 40: 553-555, 1995.

36. Peng HX, Liu XD, Luo ZY, Zhang XH, Luo XQ, Chen X, Jiang H and $\mathrm{Xu}$ L: Upregulation of the proto-oncogene Bmi-1 predicts a poor prognosis in pediatric acute lymphoblastic leukemia. BMC Cancer 17: 76, 2017.

37. Song W, Tao K, Li H, Jin C, Song Z, Li J, Shi H, Li X, Dang Z and Dou K: Bmi-1 is related to proliferation, survival and poor prognosis in pancreatic cancer. Cancer Sci 101: 1754-1760, 2010.

38. Wang Y, Zhe H, Ding Z, Gao P, Zhang N and Li G: Cancer stem cell marker Bmi-1 expression is associated with basal-like phenotype and poor survival in breast cancer. World J Surg 36: 1189-1194, 2012.

39. Lei X, Li YF, Chen GD, Ou DP, Qiu XX, Zuo CH and Yang LY: Ack1 overexpression promotes metastasis and indicates poor prognosis of hepatocellular carcinoma. Oncotarget 6: 40622-40641, 2015.

40. Yang M, Xie X and Ding Y: SALL4 is a marker of poor prognosis in serous ovarian carcinoma promoting invasion and metastasis. Oncol Rep 35: 1796-1806, 2016.

41. Thiery JP: Epithelial-mesenchymal transitions in tumour progression. Nat Rev Cancer 2: 442-454, 2002.
42. Acloque H, Adams MS, Fishwick K, Bronner-Fraser $M$ and Nieto MA: Epithelial-mesenchymal transitions: The importance of changing cell state in development and disease. J Clin Invest 119: 1438-1449, 2009.

43. Zeisberg $M$ and Neilson EG: Biomarkers for epithelial-mesenchymal transitions. J Clin Invest 119: 1429-1437, 2009.

44. Kalluri R and Weinberg RA: The basics of epithelialmesenchymal transition. J Clin Invest 119: 1420-1428, 2009.

45. Thiery JP, Acloque H, Huang RY and Nieto MA: Epithelial-mesenchymal transitions in development and disease. Cell 139: 871-890, 2009.

46. Tam WL and Weinberg RA: The epigenetics of epithelial-mesenchymal plasticity in cancer. Nat Med 19: 1438-1449, 2013.

47. Song LB, Li J, Liao WT, Feng Y, Yu CP, Hu LJ, Kong QL, $\mathrm{Xu}$ LH, Zhang X, Liu WL, et al: The polycomb group protein Bmi-1 represses the tumor suppressor PTEN and induces epithelial-mesenchymal transition in human nasopharyngeal epithelial cells. J Clin Invest 119: 3626-3636, 2009.

48. Li H, Song F, Chen X, Li Y, Fan J and Wu X: Bmi-1 regulates epithelial-to-mesenchymal transition to promote migration and invasion of breast cancer cells. Int J Clin Exp Pathol 7: 3057-3064, 2014

49. Yi C, Li BB and Zhou CX: Bmi-1 expression predicts prognosis in salivary adenoid cystic carcinoma and correlates with epithelial-mesenchymal transition-related factors. Ann Diagn Pathol 22: 38-44, 2016.

50. Liu Y, Chu Z, Li Q, Peng B, Xu S, Lian CG and Geng S: Downregulation of Bmi-1 suppresses epithelial-mesenchymal transition in melanoma. Oncol Rep 37: 139-146, 2017.

51. Zheng Z, Bao F, Chen X, Huang $H$ and Zhang $X$ : MicroRNA-330-3p expression indicates good prognosis and suppresses cell proliferation by targeting Bmi-1 in osteosarcoma. Cell Physiol Biochem 46: 442-450, 2018.

52. Joensuu K, Hagstrom J, Leidenius M, Haglund C, Andersson LC, Sariola $\mathrm{H}$ and Heikkilä P: Bmi-1, c-myc and Snail expression in primary breast cancers and their metastases-elevated Bmi-1 expression in late breast cancer relapses. Virchows Arch 459: 31-39, 2011.

This work is licensed under a Creative Commons Attribution-NonCommercial-NoDerivatives 4.0 International (CC BY-NC-ND 4.0) License. 